\title{
QUALIFICAÇÃO PROFISSIONAL: PARA ALÉM DA PROFISSIONALIZAÇÃO, UMA PERSPECTIVA SOCIAL
}

\author{
F.R.B.Andrade ${ }^{1 *}$; H.R.F.Eloy ${ }^{1}$ \\ 1 Universidade Estadual do Ceará, 60.714.903, Fortaleza-CE, Brasil \\ * rejane.bezerra@uece.br
}

Artigo submetido em 01/03/2016 e aceito em 30/04/2016

\section{RESUMO}

O objetivo do presente artigo é discutir as implicações da qualificação profissional para a inserção de jovens egressos de acolhimento institucional no mercado de trabalho. Destaca-se a análise da categoria qualificação profissional, a qual deve ser vista também como social, e como esta teve o seu planejamento e efetivação afetados pelas metamorfoses do mundo do trabalho. Tais metamorfoses também tiveram fortes repercussões na inserção do trabalhador jovem no mercado de trabalho. Nessa conjuntura serão discutidas as dificuldades e desafios encontrados por esse trabalhador $\mathrm{e}$ as implicações da qualificação profissional nesse processo, principalmente através das experiências e vivências relatadas pelos jovens entrevistados. A pesquisa teve natureza eminentemente qualitativa, tendo em seu percurso metodológico a realização de uma entrevista semi-estruturada com os jovens egressos e funcionários da instituição, aplicação de questionário com estes jovens e levantamento bibliográfico. Finalmente, afirma-se que existem muitos desafios a serem enfrentados pelos jovens que estiveram em acolhimento institucional; estes desafios implicam em várias repercussões na vida desse jovem egresso, dentre elas, a dificuldade de inserção na vida em comunidade e no mercado de trabalho.

PALAVRAS-CHAVE: Juventude, Qualificação Profissional, Mercado de Trabalho.

\section{PROFESSIONAL QUALIFICATION: BEYOND THE PROFESSIONAL, A SOCIAL PERSPECTIVE}

\begin{abstract}
The purpose of this article is to discuss the implications of the professional qualification for the inclusion of young graduates of residential care in the labor market. Noteworthy is the analysis of professional qualification category, which should also be seen as social, and how this had its planning and execution affected by the metamorphoses of the world of work. Such metamorphoses also had strong repercussions in the insertion of young workers in the labor market. At this juncture will discuss the difficulties and challenges encountered by the worker and the implications of the professional qualification in that process, especially
\end{abstract}

through the experiences and experiences reported by young people interviewed. The study was essentially qualitative, in his methodological approach to conducting a semi-structured interviews with young graduates and employees of the institution, a questionnaire with these young people and literature. Finally, it is stated that there are many challenges to be faced by young people who were in institutional care; these challenges involve several repercussions on the life of this young graduate, among them the inclusion of difficulties in community life and in the labor market.

KEYWORDS: Youth, Vocational Training, Labour Market. 


\section{INTRODUÇÃO}

Esse artigo centra suas análises sobre as implicações da qualificação profissional na inserção de jovens egressos de acolhimento institucional no mercado de trabalho. Nesse contexto, é fundamental discutirmos a qualificação profissional para compreendermos tais implicações.

Não podemos falar de qualificação profissional sem abordarmos o fato de que a profissionalização consiste em um direito assegurado pela Constituição Federal do nosso país. No que discerne a profissionalização de adolescentes e jovens até os 18 anos de idade, ela é regulamentada pelo Estatuto da Criança e do Adolescente - ECA - no seu capítulo V, onde estão designados direitos e deveres do jovem trabalhador, reiterando as indicações da Constituição e da Consolidação das Leis Trabalhistas (CLT), esta vem reiterar as indicações da Constituição quanto à idade mínima para o trabalho, restrições a alguns tipos de trabalho e cita a modalidade de trabalho do aprendiz.

De acordo com o ECA, o adolescente pode se ocupar como aprendiz na faixa etária entre 14 e 18 anos, quando deve receber uma atenção especial quanto ao regime de tempo limitado de trabalho e ao seu processo de aprendizagem profissional e escolar. Após completar 16 anos e até os 18 anos, o jovem pode ser trabalhador assalariado, mas ainda com restrições a trabalhos penosos, insalubres ou perigosos. Depois de completar 18 anos, o trabalho do jovem é regulado como o dos trabalhadores adultos. É interessante ressaltarmos que em qualquer uma dessas condições, o trabalhador jovem goza de direitos trabalhistas, bem como os demais trabalhadores em geral.

Nas políticas de implantação da profissionalização encontramos as políticas de qualificação profissional e é a esta que nos debruçaremos neste momento. Inicialmente, é necessário destacarmos o fato de que uma política de qualificação profissional é classificada dentre as políticas ativas de emprego. Conforme Azeredo (1997, p. 57), tais políticas têm um papel essencial a cumprir na socialização e integração dos excluídos do mercado de trabalho, na preservação da qualificação da força de trabalho desocupada, na geração de atividades à margem do setor moderno da economia, e, em alguns casos, na elevação dos padrões de organização e consciência social. No Sistema Brasileiro de Proteção Social, a qualificação para o trabalho está entre as políticas organizadas com base no eixo emprego e trabalho, juntamente com a Previdência Social; previdência e benefícios de servidores públicos; políticas de apoio ao trabalhador; políticas ligadas à organização agrária e à política fundiária. (CARDOSO Jr.; JACCOUD, 2005).

\section{REVISÃO BIBLIOGRÁFICA}

Não é tarefa simples definirmos o que é qualificação, visto que trata-se de um conceito multifacetado, existindo, portanto, diversas acepções para o termo. Além disso, é necessário analisarmos as práticas envolvidas nesse âmbito dentro de uma perspectiva de qualificação como uma construção sociocultural. Nessa perspectiva, corroboramos com a seguinte afirmação de Lima:

A qualificação, mais do que o aprendizado de um conjunto das rotinas vinculadas a um posto de trabalho, centrada no saber-fazer,implica, por ser relação e construção social - complexa, contraditória e multideterminada - a percepção ampla de seus objetivos, conteúdos e métodos, o que incluiria, por exemplo, a dimensão social do trabalho, a autonomia do trabalhador e as qualificações tácitas, construídas no cotidiano do trabalho. (LIMA, 2007, p. 63).

Após conceituarmos, dentro do nosso entendimento e da proposta desse artigo, o que seria a qualificação profissional, faz-se necessário um breve resgate histórico dessa política no nosso país.

Somente na década de 1990, com o advento do Fundo de Amparo ao Trabalhador (FAT) e, por conseguinte, com os cursos financiados por esse fundo, ganhou força no país, a perspectiva de 
estruturar cursos de qualificação profissional voltados para os jovens em situação de vulnerabilidade social, onde se encontram os jovens institucionalizados e, consequentemente, os que estão em acolhimento institucional, realidade que fez parte da vida dos jovens que participaram dessa pesquisa. Assim, ao invés de se destinar para a classe trabalhadora em geral, estes cursos visavam os jovens das comunidades mais pobres, com a intenção de enfrentar sua marginalização e, até mesmo, seu envolvimento com a criminalidade (IPEA 2009). O Ministério do Trabalho retomou a iniciativa no campo da política pública de qualificação profissional através do FAT e em 1993, iniciaram-se ações voltadas à qualificação profissional dos beneficiários do seguro-desemprego e funcionários do SINE. Contudo, somente em 1995 foi instaurado no Brasil, o Plano Nacional de Qualificação Profissional - PLANFOR. No tocante a importância da consolidação do FAT, Ramos afirma:

(...) primeiro, porque definiu recursos próprios para o Sistema Público de Emprego, tornando-o independente com relação ao tesouro nacional; segundo, porque este fundo passou a ser gerido por um conselho deliberativo (CODEFAT), com representação tripartite e paritária, composto por representantes do empresariado, do governo e dos trabalhadores. Ou seja, o FAT é um arranjo institucional que procura garantir a execução de políticas públicas de emprego e renda de maneira descentralizada e participativa. (RAMOS, 2006, p. 45).

Entre os anos de 1995 e 2002, vigorou no país o Plano Nacional de Qualificação do Trabalhador (PLANFOR), que surgiu em paralelo à rede de educação profissional e tecnológica que já existia no sistema de ensino brasileiro, pois, para os elaboradores do Plano, esta rede não atendia a demanda dos trabalhadores mais pobres (IPEA 2009). O PLANFOR passou a tratar a qualificação profissional como política pública, integrando-a ao conjunto de ações destinadas a estimular oportunidades de geração de trabalho e renda. No que diz respeito à concepção de qualificação, sobressai no âmbito do PLANFOR à noção de competência. Segundo o Ministério do Trabalho:

Delineia-se neste contexto um novo perfil e um novo conceito de qualificação, que vai além do simples domínio de habilidades manuais e/ou disposição para cumprir ordens (...). O novo perfil valoriza traços como participação, iniciativa, raciocínio, discernimento, informação. Buscam-se pessoas com iniciativa, capacidade de decidir e agir em face de imprevistos ou eventos aleatórios - que são tanto mais frequentes quanto mais modernas, integradas e informatizadas as empresas. (MTE/SPPE/DEQP, 2001, p. 54).

De acordo com Moretto (2007), o Plano teve como premissa a ideia de que o desemprego era consequência do processo de reestruturação produtiva aliado à baixa qualificação do trabalhador brasileiro. Contudo, o PLANFOR enfrentou fortes críticas, sobretudo, nos seguintes aspectos: incapacidade de se integrar efetivamente às demais Políticas Públicas de Trabalho e Renda e de interagir decisivamente com as Políticas Públicas de Educação; fragilidade das Comissões Estaduais e Municipais de Trabalho (CETs e CMTs); baixo grau de institucionalidade da rede nacional de qualificação profissional; ênfase nos cursos de curta duração; fragilidade do seu sistema de planejamento, monitoramento e avaliação. (MTE/SPPE/DEQ, 2003, p.19).

Nessa conjuntura se instituiu novas diretrizes para a qualificação profissional no Brasil, que culminaram com a criação, em 2003, do novo Plano Nacional de Qualificação- PNQ. Este vive o desafio de afirmar o seu caráter público e sua referência na qualificação profissional enquanto um direito social. Tal perspectiva pode ser comprovada na seguinte afirmação: 
Na concepção do novo Plano Nacional de Qualificação - PNQ, foi feito o esforço de combinar todas as ações de Políticas Públicas de Emprego (Intermediação de Mão-de-Obra, Programa de Geração de Emprego e Renda, Seguro-Desemprego) para que de fato todo esse processo seja inclusivo para os que procuram uma forma de trabalho ou renda, a fim de tornarem-se cidadãos. (BRASIL, 2003, p. 7).

O PNQ traz como objetivos: a inclusão social e a redução das desigualdades sociais; o crescimento com geração de trabalho, emprego e renda, ambientalmente sustentável e redutor das desigualdades regionais; a promoção e expansão da cidadania; e o fortalecimento da democracia (MTE, 2003, p. 9). O PNQ focou suas ações em três tipos de atendimento: Planos Territoriais de Qualificação (em parceria com estados, municípios e entidades sem fins lucrativos), Projetos Especiais de Qualificação (em parceria com entidades do movimento social e organizações não governamentais) e Planos Setoriais de Qualificação (em parceria com sindicatos, empresas, movimentos sociais, governos municipais e estaduais). Com base no exposto coadunamos com a ideia de que o PNQ significou:

Uma Política Pública de Qualificação, que venha a se afirmar como um fator de inclusão social, de desenvolvimento econômico, com geração de trabalho e distribuição de renda, deve nortear-se por uma concepção de qualificação entendida como uma construção social, de maneira a fazer um contraponto àquelas que se fundamentam na aquisição de conhecimentos como processos estritamente individuais e como uma derivação das exigências dos postos de trabalho. (BRASIL, 2003, p. 23).

A partir de 2007, a oferta de cursos de qualificação se ampliou no Brasil devido à diversificação dos programas e à conexão com programas de investimento em infraestrutura, programas de assistência social, transferência de renda, economia solidária, fomento ao empreendedorismo e inserção de jovens. A oferta de cursos de qualificação foi intensificada, principalmente, nas áreas metropolitanas, devido à diversificação da política de trabalho e a sua articulação com o Programa de Aceleração do Crescimento (PAC), as políticas de assistência social, combate à pobreza e transferência de renda e os programas de inclusão social de jovens.

Constatamos, portanto, que o aumento na oferta desses cursos ocorrido no Brasil desde 2007, decorre das várias ações de capacitação e qualificação para o trabalho, desenvolvidas pelo Governo Federal, orientadas principalmente aos segmentos atendidos em programas de combate à pobreza e mais vulneráveis no mercado de trabalho.

Após essa breve incursão sobre a política de qualificação profissional no país, destacamos que o Brasil avançou, principalmente nos anos 2000, no desenvolvimento de programas que utilizam a qualificação profissional como uma forma de auxiliar o jovem a ingressar no mercado de trabalho e diminuir a exclusão social, que afeta grande parte da nossa juventude. Dentre os programas, vale destacar: o Programa Nacional de Estímulo ao Primeiro Emprego (PNPE), O Programa Nacional de Inclusão de Jovens (ProJovem) e o Programa Nacional de Acesso ao Ensino Técnico e Emprego (PRONATEC), os quais não cabem ser detalhados nesse artigo.

Com base no exposto, percebemos que as políticas públicas de emprego, onde destacamos a qualificação profissional, seguem o ritmo das demais políticas sociais no nosso país, ou seja, tendem à focalização nos segmentos mais vulneráveis socialmente, imprimindo um conceito de qualificação para pobres, com uma forte conotação assistencial por parte das instituições de gestão e execução. 
Não se afirma, contudo, que esta focalização não se faz necessária, afinal são as pessoas que se encontram em vulnerabilidade social que estão geralmente em posição de desvantagem no mercado de trabalho e que, por essa razão, se submetem aos trabalhos mais precários e desprotegidos, necessitando, portanto, de oportunidades para se qualificarem a fim de tentarem um emprego melhor. A questão que se apresenta é que a qualificação profissional não deve ser idealizada e vista como uma "política para pobres", pois causa no imaginário social, a errônea e equivocada concepção de que a culpa da inserção em trabalhos subalternos é do indivíduo, que não se qualificou o suficiente, e não do sistema econômico. Nessa perspectiva:

A própria efetividade do programa de qualificação é questionada, na medida em que as empresas tendem a não privilegiar a qualificação de mão de obra. $\mathrm{Ou}$ seja, a qualificação funciona como discurso ideológico, ao oferecer cursos para os desempregados, acaba por transferir a responsabilidade para a vítima, pois se o trabalhador não conseguir trabalho mesmo com a ajuda de um curso de qualificação, o fracasso é somente dele. (DEDECCA apud MORETTO, 2007, p. 168).

Nesse contexto, a juventude se sente ainda mais pressionada a realizar a qualificação profissional, visto que o jovem encontra grande dificuldade de ingressar no mercado de trabalho por não ter "experiência", então, nessa óptica da culpabilização do indivíduo, ele acredita que realizando cursos de qualificação profissional conseguirá um emprego, percepção essa reafirmada quando se percebe que a maioria dos programas de qualificação profissional do nosso país tem como foco a juventude. políticas:

É dentro dessa realidade que vale citar Sposito e Carrano, quando estes afirmam que estas

Assumiram o fetiche da capacitação do jovem para um mercado de trabalho de poucas oportunidades, sem propor qualquer caminho de questionamento da realidade econômica e social de um período histórico que viveu a recessão provocada pelas altas taxas de juros e os efeitos agudos da crise do mundo do trabalho. (SPOSITO, CARRANO, 2003, p. 31).

Portanto, percebe-se que uma das consequências da ofensiva neoliberal nas políticas sociais culminou na propagação da qualificação profissional como fator essencial na promoção da inserção dos trabalhadores no mercado de trabalho. Sobre essa realidade, Castel alertava para a possível "não empregabilidade dos qualificados", e para o fato de que "é ilusório deduzir daí que, os nãos empregados possam encontrar um emprego, simplesmente pelo fato de uma elevação do nível de escolaridade". (1998, p.521).

Até aqui, refletimos sobre a qualificação profissional e suas características enquanto política pública. Após essa explanação é pertinente refletir sobre a forma como a política de qualificação profissional se efetiva na Casa do Menor São Miguel Arcanjo, afinal, foi nessa instituição onde os jovens participantes da pesquisa ora apresentada realizaram os cursos de qualificação profissional e o acolhimento institucional.

\section{MATERIAIS E MÉTODOS}

A Casa do Menor São Miguel Arcanjo - CMSMA realiza cursos de qualificação profissional com os educando internos da instituição na cidade de Fortaleza, Ceará. Esses cursos são abertos à comunidade, propiciando um momento de interação entre os jovens que estão no abrigo e os jovens da comunidade. Sobre essa interação, a assistente social da instituição afirma: 
Isso daí é de grande importância, porque eles têm direito a convivência comunitária e isso tem que ser preservado. Eles estão aqui, esse direito já é violado né? Eles estão aqui, não estão presos, mas eles não podem sair a hora que querem. (Assistente Social da CMSMA)

Os cursos ofertados por essa instituição são os de Informática Básica, Auxiliar Administrativo e Cabeleireiro. O curso de Auxiliar Administrativo é o único da instituição que tem convênio com o Ministério do Trabalho e, por essa razão, a instituição consegue fazer o encaminhamento para o mercado de trabalho, através do Programa Jovem Aprendiz. Por meio deste curso, os alunos realizam uma aprendizagem profissional. Devido à possibilidade de encaminhamento para o mercado de trabalho, esse curso é o mais requisitado da instituição, tanto pelos educandos internos, quanto pelos demais jovens. Todos os quatro jovens que participaram da pesquisa, por exemplo, realizaram esse curso. Tal situação será mais bem explanada posteriormente, quando será abordada a implicação da qualificação profissional para a inserção no mercado de trabalho do jovem egresso da CMSMA.

A verba para a realização dos cursos provém da própria instituição, os jovens externos pagam um valor de 35 reais mensais e a cada mudança de módulo, eles pagam 20 reais pela apostila. Esses pagamentos auxiliam a instituição a manter os cursos de qualificação profissional. $\mathrm{O}$ poder público não ajuda a instituição na manutenção dos cursos profissionalizantes, mesmo se tratando de uma instituição com curso reconhecido pelo MTE e participante de programas federais de qualificação profissional (Jovem Aprendiz).

Para melhor compreender a realidade do jovem egresso de acolhimento institucional, considera-se essencial apresentar o perfil dos jovens que participaram dessa pesquisa, a fim de esclarecer como esses jovens estão vivendo após o acolhimento e quais as implicações da qualificação profissional na vida profissional e pessoal desse jovem.

Antes disso, vale destacar que a pesquisa teve natureza eminentemente qualitativa, tendo em seu percurso metodológico a realização de uma entrevista semi-estruturada com os jovens egressos e funcionária da instituição, aplicação de questionário com estes jovens e levantamento bibliográfico.

Os jovens que participaram da pesquisa realizaram o acolhimento institucional na Casa do Menor São Miguel Arcanjo. De acordo com Moreira (2013, p. 18), até o ano de 2012 a referida instituição tinha 504 jovens egressos, sendo que destes, 271 tinham idade entre 18 e 24 anos. Os jovens realizaram os cursos de qualificação profissional na referida instituição, foram desinstitucionalizados por terem atingido a maioridade civil (18 anos) e estão na faixa etária entre 19 e 25 anos.

Em seguida, tabela 1, apresenta-se um breve perfil desses jovens, principalmente no que tange à qualificação profissional recebida na instituição e à inserção no mercado de trabalho.

Tabela 1 - Perfil dos Jovens

\begin{tabular}{|l|c|c|c|c|}
\hline Nome Fictício & Idade & Raça & Renda Mensal & Tempo de acolhimento \\
\hline Hermes & 19 anos & Pardo & $1,5 \mathrm{SM}$ & 3 anos \\
\hline Apolo & 21 anos & Pardo & $1 \mathrm{SM}$ & 4 anos \\
\hline Thor & 22 anos & Negro & $1 / 2 \mathrm{SM}$ & 8 anos \\
\hline Hércules & 25 anos & Pardo & $1 \mathrm{SM}$ & \\
\hline
\end{tabular}

Fonte: Produção Própria, 2015.

Através da aplicação de um questionário com esses jovens traçou-se o perfil socioeconômico, e por meio das entrevistas semiestruturadas, que foram aplicadas individualmente, 
foram captadas suas perspectivas de vida e suas experiências de aprendizagem nas diversas situações vividas durante e após a institucionalização.

Como se percebe, todos os jovens que participaram da pesquisa ficaram na instituição mais de dois anos, contrariando o que preconiza o ECA, que afirma que este deve ser o tempo máximo de acolhimento. Assim, identifica-se fragilidades quanto a eficácia de políticas públicas no cumprimento do que está estabelecido no referido Estatuto.

É interessante ressaltar que o perfil social dos meninos é o mesmo da maioria dos acolhidos institucionalmente no país. Segundo o IPEA (2003), o perfil da maioria dos abrigados no Brasil corresponde a crianças e adolescentes do sexo masculino (58,5\%), afro-descendentes $(63,6 \%)$, com idade entre sete e quinze anos $(61,3 \%)$, sendo que $55,2 \%$ das crianças e adolescentes que estão em abrigos permanecem lá por um período de sete meses a cinco anos, observando que a parcela mais significativa (32,9\%) está no abrigo há um período entre dois e cinco anos, ainda que a medida de abrigo seja estabelecida como excepcional e provisória. Percebe-se então que o perfil dos acolhidos institucionalmente no Brasil perpassa por um recorte de gênero e etnia; e que as políticas públicas para esse público alvo precisam ser debatidas e redimensionadas, visto que não estão atingindo a eficácia necessária, pois muitos dos abrigados estão ficando mais de dois anos nos abrigos.

É pertinente se pontuar também que a maioria dos jovens entrevistados tem uma renda mensal de no máximo um salário mínimo, ou seja, mesmo quando esses jovens se inserem no mercado de trabalho não têm uma boa remuneração. Um dos jovens chega a receber menos de um salário mínimo, como ele expõe: "eu procurei bastante, mas ninguém queria dar emprego para um menino de 18 anos... aí apareceu a oportunidade lá na "churrascaria", aí tô lá até hoje... não vou dizer que era meu sonho, mas também não é o fim do mundo" (Thor, 22 anos). Nessa conjuntura, fica complicado esse jovem conseguir romper o ciclo de pobreza no qual está inserido desde a infância, afinal, todos os jovens entrevistados foram acolhidos por falta de condições financeiras de suas famílias para sustentarem e proverem suas necessidades básicas. Percebe-se, portanto, que as desigualdades materiais geram as desigualdades de direitos e de pertencimento social. Deste modo, vivemos em uma organização socioeconômica pautada nas desigualdades, na exploração e nas contradições.

Faz-se necessário, portanto, que as políticas públicas de emprego e as políticas públicas para juventude sejam efetivadas, e pensem nessa juventude institucionalizada como uma expressão da questão social e que necessita que suas especificidades sejam contempladas. Assim, de acordo com Santos (2009):

Após a institucionalização. Sendo a Instituição e a Escola os principais agentes de socialização destas crianças e, consequentemente os principais transmissores de educação, valores e competências. É necessário que ambas as Instituições trabalhem em conjunto, com o objetivo de impedir a exclusão das crianças em contexto escolar, exclusão esta que é consequência de uma outra forma de exclusão (nível sócio-econômico, história de vida...) e, que poderá provocar mais uma exclusão - exclusão social, ou seja são crianças e jovens que à partida são rejeitados socialmente, podendo-se perpetuar até à fase adulta se não forem aplicados os mecanismos de prevenção necessários à sua efetiva (re)inserção. (2009, p. 1).

Apesar da limitação quanto à oferta de cursos, a instituição estimula bastante os jovens a realizarem os cursos de qualificação profissional. Atualmente, segundo a assistente social da instituição, só há um jovem com idade entre 15 e 17 anos que está acolhido. Ela afirma que ele já realizou o curso de informática básica e que não se interessou em realizar nenhum dos outros cursos 
ofertados pela instituição. Na época da pesquisa, realizada no segundo semestre de 2015, o jovem estava realizando cursos na Rede CUCA e a Casa do Menor providenciava o transporte. Vemos, assim, que há um esforço por parte da instituição para que esse jovem tenha assegurado o seu direito à convivência comunitária, e realize cursos de qualificação profissional. $\mathrm{O}$ mesmo pode ser observado na seguinte fala de um dos jovens entrevistados:

A tia lá sempre dizia pra gente fazer os cursos, que era importante, que ia ajudar a gente a conseguir um emprego, a ter uma vida melhor. Aí eu ficava pensando que esses cursos eram uma chance sabe? Tipo, eu não ia ter muitas chances então eu tinha que pegar todas que aparecesse, aí eu fiz o curso de auxiliar e de informática. Não é que pronto, fiz o curso aí tô empregado, mas pelo menos meu currículo não tá vazio né? Já é um começo. (Thor, 22 anos).

Contudo, os jovens da instituição não são consultados quanto aos cursos ofertados. Estes são realizados de acordo com a realidade da instituição e não de acordo com a demanda dos jovens.

Infelizmente isso daí não é visto com eles, é de acordo com a realidade da estrutura que a gente pode ofertar. (...) O auxiliar administrativo é o único que a gente consegue encaminhar para o mercado de trabalho, então, esse sempre vai ter, porque a gente tem uma demanda muito grande. (Assistente Social da CMSMA).

Seria relevante que esses jovens fossem consultados quanto aos cursos a serem ofertados na instituição, para que se sentissem participantes do processo, e não realizassem o curso porque ele encaminha para o mercado de trabalho. Ações desse tipo contribuem para que as políticas de qualificação profissional sejam vistas de maneira focalizada e minimalista. Entretanto, entende-se que a instituição pesquisada esbarra em entraves institucionais e financeiros.

Importa destacar que a qualificação profissional foi bastante relevante na vida dos entrevistados. Todos relataram o quanto ela foi importante, tanto no âmbito pessoal quanto no profissional. Para esses jovens, a qualificação profissional trouxe novas perspectivas e ampliou a convivência comunitária.

Olha, a hora dos cursos era uma das melhores da semana, tipo, tinha a escola quando eu via o pessoal que morava fora da Casa do Menor, mas tipo era fora entende? Era difícil um momento que o pessoal de fora vinha aqui, e na hora dos cursos eles tavam na minha casa sabe? Tipo, eles iam na Casa do Menor, faziam o mesmo caminho que eu lá dentro, jogavam na minha quadra, eles entravam no meu mundo... (silêncio) e isso, ah isso não tem palavras. (...) Os cursos me trouxeram muita coisa boa, pensei até em fazer faculdade (risos) imagina só eu na faculdade (risos), sei lá, gostei desse negócio de administração, acho que seria um bom administrador, aí pensei em cursar administração, mas não passei no vestibular e também não tenho dinheiro, aí tô só trabalhando mesmo agora (silêncio), mas um dia quem sabe né? Ano que vem vou tentar o PROUNI. Antes do curso eu não sabia o que fazer, pensava em ser marceneiro, mas hoje eu sei que quero fazer administração, pelo menos ainda tô trabalhando na área. (Apolo, 21 anos).

O relato do jovem mostra o quanto a qualificação profissional pode significar para quem a vivencia, sendo, assim, necessário pensá-la para além do âmbito profissional, concebendo-a também dentro de uma perspectiva social. Com o advento do PNQ essa perspectiva foi introduzida nos objetivos da política de qualificação profissional. Na fala do jovem observa-se ainda o fato de o 
abrigo passar a representar um lar para as crianças e adolescentes que lá vivem. Isso se dá devido ao tempo que eles passam no abrigo, geralmente mais de dois anos, o que fere o caráter de transitoriedade que o abrigo deveria ter.

\section{RESULTADOS E DISCUSSÃO}

Um fator bastante relevante a ser elucidado é o fato de que todos os jovens entrevistados realizaram o curso de auxiliar administrativo, como já exposto no capítulo anterior. Segundo a assistente social da instituição, este é o único que faz encaminhamento para o mercado de trabalho, assim, os jovens são bastante estimulados a realizar esse curso, reforçando a lógica do trabalho como meio de sobrevivência, reconhecimento e inserção social, principalmente, na sociedade atual.

Apesar de haver encaminhamento para o mercado de trabalho, a pesquisa revela que apenas um jovem trabalha na área que realizou o curso (Ver Tabela 2). Os outros, como explicitado nas entrevistas, trabalham em outras áreas por razão de não terem se identificado com o setor administrativo; ou pelo contrato da empresa onde realizaram o PROJOVEM não ter efetivado o jovem, e terem surgido oportunidades para trabalhar em outras áreas.

Tabela 2- Dados dos Jovens Entrevistados

\begin{tabular}{|c|c|c|c|c|c|}
\hline $\begin{array}{c}\text { Nome } \\
\text { Fictício }\end{array}$ & Curso que realizou & $\begin{array}{c}\text { Trabalha } \\
\text { atualmente }\end{array}$ & $\begin{array}{c}\text { Trabalha na área } \\
\text { do curso que } \\
\text { realizou }\end{array}$ & $\begin{array}{c}\text { Local onde } \\
\text { trabalha }\end{array}$ & $\begin{array}{c}\text { Trabalha com } \\
\text { Carteira } \\
\text { assinada }\end{array}$ \\
\hline Hermes & $\begin{array}{c}\text { Assistente } \\
\text { Administrativo }\end{array}$ & Sim & Não & $\begin{array}{l}\text { Sargento do } \\
\text { exército }\end{array}$ & Sim \\
\hline Apolo & $\begin{array}{c}\text { Assistente } \\
\text { Administrativo }\end{array}$ & Sim & Sim & $\begin{array}{c}\text { Loja de peças } \\
\text { automobilísticas }\end{array}$ & Sim \\
\hline Thor & $\begin{array}{c}\text { Assistente } \\
\text { Administrativo e } \\
\text { Informática }\end{array}$ & Sim & Não & Churrascaria & Não \\
\hline Hércules & $\begin{array}{c}\text { Assistente } \\
\text { Administrativo e } \\
\text { Informática }\end{array}$ & Sim & Não & Construção civil & Sim \\
\hline
\end{tabular}

Fonte: Elaboração própria, 2015.

Esse quadro traz a reflexão sobre a eficácia do encaminhamento desses jovens ao mercado de trabalho e sobre a importância da realização pessoal ser colocada dentro da perspectiva da realização da qualificação profissional. Afinal, esses jovens, mesmo que não se identifiquem com o curso de auxiliar administrativo, realizam o mesmo na expectativa de se inserirem no mercado de trabalho, contudo, esse objetivo não está sendo alcançado. O jovem deixa de fazer um curso que talvez tivesse maior interesse e acaba se frustrando por não ter realizado um curso que lhe despertasse maior interesse, e por não ter conseguido se inserir no mercado de trabalho, mesmo realizando o curso que lhe daria mais oportunidades para tal. Observe o relato de um dos jovens:

Assim, eu não gostei de trabalhar na área administrativa, é muito chato e é cheio de coisa "cri cri" pra fazer. Eu não gostava de passar o dia na frente do computador fazendo aquele monte de tabela... achava muito chato... mas, assim, eu fazia tudo bem direitinho, era uma oportunidade de eu conseguir um emprego sabe? Mesmo sem ser em uma coisa que eu goste, e tipo... gente assim, que nem eu, não pode ficar por aí escolhendo emprego não. Se eu tivesse sido efetivado eu teria ficado lá certeza, mas aí não deu certo, não me chamaram, aí fui trabalhar de garçom, depois numa loja e hoje to trabalhando de pedreiro... é muito cansativo, mas eu gosto muito. Nesse 
trabalho de hoje eu consigo ver a diferença de trabalhar numa coisa que a gente goste, é meio que um bônus né (risos)? (Hércules, 25 anos).

Portanto, a necessidade de se inserir no mercado de trabalho é ainda mais presente para os jovens em situação de vulnerabilidade social, como os que viveram em acolhimento institucional e que a realização profissional vem em primeiro lugar, antes mesmo da realização pessoal. Para estes jovens, a inserção no mercado de trabalho representa a sobrevivência após a saída da instituição e pode significar um passaporte para retornar a sua família de origem. Para os jovens de classes menos abastadas, o trabalho é uma obrigação, muitas vezes, um fardo, não sendo concebido como algo que pode ser prazeroso, e sim como uma necessidade latente.

Olha, eu ficava todo tempo pensando como é que eu ia viver, comprar minha coisas, eu precisava de um trabalho e isso me deixava nervoso. Eu precisava de qualquer coisa, pagando bem ou mal, que fosse bom ou ruim para mim, só tinha que ser um trabalho honesto. Também achava que se eu tivesse um emprego era mais fácil do povo lá de casa me querer de volta com eles, tipo, eu já era grande sabe? Aí voltar depois de um tempo sem ter nada pra colocar dentro de casa era mais difícil, eu pensava que ninguém ia querer mais uma boca inútil pra alimentar. Já saí de casa porque não tinham dinheiro e voltar pra lá sem ter também era sem sentido. Serio, eu só pensava que tinha que ter um emprego. (Apolo 21 anos).

Esses jovens vivem em um processo que dificulta o seu desenvolvimento e o seu aprimoramento profissional, visto que a latente necessidade de inserção no mercado de trabalho faz com que eles se submetam ao mercado informal e ao subemprego. Conforme Oliveira (2001):

Conseguir um trabalho regular é mais difícil, em virtude das maiores exigências de qualificação. A dificuldade de encontrar trabalho também faz com que alguns jovens diminuam suas expectativas referentes à profissão que gostariam de seguir e se conformem com o que, no momento, é possível. (2001, p. 81).

Em um mercado de trabalho cada vez mais competitivo e exigente, onde o funcionário multifuncional é mais valorizado, esses jovens se encontram em desvantagens, tanto técnica quanto emocionalmente. Por essa razão, muitos desses jovens, geralmente, conseguem empregos de baixa remuneração, como na maioria das vezes, eles se mantêm sozinhos, acabam tendo de ter dois empregos ou fazer muitas horas extras para poderem complementar a renda. Ainda conforme Oliveira:

Para esses jovens, o trabalho é indispensável. É uma necessidade. É a possibilidade de realização de projetos profissionais futuros e a garantia de sobrevivência presente. Não há como pensar em abandonar o trabalho, muitos têm registro em carteira, também porque não está fácil conseguir um emprego hoje, dizem. Estão, portanto, vinculados ao trabalho pela necessidade, divorciada, muitas vezes, do interesse pelo trabalho em si. (2001, p. 136).

A inserção no mercado de trabalho significa, para esses jovens, reconhecimento e inserção social. Numa sociedade, onde o trabalho é um dos fatores que caracterizam o pertencimento na sociedade, estar inserido no mercado de trabalho para a juventude, muitas vezes, significa estar inserida na sociedade. A juventude que passou pelo acolhimento institucional até a maioridade, já tem dificuldade de se encontrar na sociedade devido à ausência de um apoio familiar e ao estigma 
que a sociedade impôs a ela, ao não conseguirem um trabalho se sentem duplamente excluídos. Para Castel (1998):

Uma relação salarial comporta um modo de remuneração da força do trabalho, o salário- que comanda amplamente o modo de consumo e o modo de vida dos operários e de sua família -, uma forma da disciplina do trabalho que regulamenta o ritmo da produção, e o quadro legal que estrutura a relação de trabalho, isto é, o contrato de trabalho e as disposições que o cercam. (p.419).

No tocante a qualificação profissional, esta foi muito importante na vida desses jovens. Segundo os relatos, ela lhes trouxe novas perspectivas, contudo, não foi muito efetiva na inserção destes no mercado de trabalho:

Olha, eu não trabalho na área de auxiliar (se referindo ao curso de auxiliar administrativo), mas faria o curso de novo. Eu conheci muita gente legal, fiz amigos, fiz estágio, aprendi coisa nova. Eu nem gostava muito do curso, mas só de saber que tava aprendendo algo que poderia ajudar no meu futuro já tava valendo. Quando eu terminei o curso eu pensava diferente, pensava em fazer mais, querer mais, mais cursos, mais conhecimento, eu pensava em crescer sabe? Subir na vida. (Thor, 22 anos).

Caramba, se achei importante pra minha vida ter feito o curso (risos)? Eu só achei, e até hoje acho, no começo eu não queria muito não fazer o curso, mas aí a tia (se referindo a assistente social) ficou falando que ia ser importante, que ia me ajudar a conseguir um emprego... aí eu fui né? E eu gostei muito, achava aquelas coisas muito legal, pensei em fazer faculdade naquela área, ainda não fiz, mas vou fazer, ainda to na área, o que é um começo. (Apolo, 21 anos).

O curso de auxiliar era bom, mas o de informática era o melhor de todos (risos), sai de lá pensando que tinha nascido pra fazer aquilo, ainda penso. Queria fazer faculdade de computação, hoje com a minha filha é um pouco mais difícil porque ela gasta muito dinheiro (risos), mas vou fazer, tá anotando aí no papel que eu vou fazer uma dia (risos)? (Hércules, 25 anos).

Nenhum dos quatro jovens entrevistados permaneceu na instituição na qual realizou o estágio, para eles, a instituição só os aceitava porque eram obrigadas e não tinham intenção de efetivá-los após o término do contrato. Apesar dessa situação, os jovens consideram que ter feito um curso de qualificação profissional é importante para sua inserção no mercado de trabalho: "eu trabalho numa área nada a ver com o curso que eu fiz, mas eu sei que quando eu vou procurar emprego e tem lá no currículo que eu fiz o curso conta alguma coisa" (Thor, 22 anos), "certeza que a empresa só me contratou porque eu tinha feito o curso, tipo, eu trabalho na área administrativa lá da loja, se eu não tivesse feito o curso não ia tá lá né?" (Apolo, 21 anos). Portanto, para esses jovens a qualificação profissional teve implicações tanto na vida pessoal quanto na vida profissional.

\section{CONCLUSÃO}

As recentes transformações no mercado de trabalho destacaram a qualificação sob outro prisma, tornando-a importante nas decisões governamentais de financiamento das políticas compensatórias de emprego (POCHMANN, 2002, p.122). Contudo, como foi analisado, as políticas 
tradicionais do sistema público de emprego, entre elas a de qualificação, não são eficazes para enfrentar a situação de heterogeneidade e precariedade do mercado de trabalho brasileiro (CARDOSO Jr., JACCOUD, 2005, p. 171). Nessa perspectiva, desenvolveu-se no Brasil uma estreita vinculação entre essas políticas e as de assistência social.

Portanto, reconhece-se a insuficiente conexão, mesmo após 20 anos de ações executadas no âmbito do FAT, entre os programas do Sistema Público de Emprego e os demais programas voltados para a qualificação profissional dos trabalhadores existentes em iniciativas governamentais.

A qualificação profissional deve ser um fator integrante do Sistema Público de Emprego, Trabalho e Renda, requerendo o fortalecimento do CODEFAT e das Comissões Estaduais e Municipais de Emprego, como condição de uma participação e controle sociais efetivos. Defende-se também que essa qualificação deve estar articulada às Políticas Públicas de Educação e de Desenvolvimento.

A qualificação profissional deve ser encarada para além de uma ação formativa de conteúdo técnico, visando uma inclusão produtiva no mercado de trabalho. A qualificação deve orientar-se para buscar uma inclusão cidadã, tratando-se, portanto, de uma qualificação social e profissional.

A qualificação social pode ser definida por meio da promoção de ações que contribuam para a formação holística do indivíduo, dando-lhe acesso a conhecimentos importantes para a vida em sociedade e permitindo que se torne sujeito de direitos, partindo não apenas de aulas teorias, mas criando situações reais de aprendizado, tais como atividades que permitam o acesso à cultura. (SOARES, 2013, p.303).

Coaduna-se com a ideia de que a qualificação profissional deve ser afirmada na perspectiva do direito social, devendo, portanto, ser objeto de uma política nacionalmente articulada, controlada socialmente, sustentada publicamente e orientada para o desenvolvimento sustentável, a inclusão social e a consolidação da cidadania.

No desenvolver desse artigo foi perceptível que as políticas públicas de emprego, onde se destaca a qualificação profissional, segue o ritmo das demais políticas públicas do país, ou seja, tende a focalização nos segmentos mais vulneráveis socialmente, imprimindo, assim, um conceito de qualificação para pobres, com uma forte conotação assistencial por parte das instituições de gestão e execução.

Na pluralidade da juventude, destaca-se a juventude que viveu em acolhimento institucional até a maioridade, colocando em pauta, através do olhar do jovem egresso da Casa do Menor São Miguel Arcanjo, os seus desafios e suas perspectivas.

Conclui-se o quanto é importante que na instituição visitada - CMSMA, os cursos de qualificação profissional sejam feitos com a presença de jovens externos à instituição, pois é uma das formas do jovem acolhido fortalecer a convivência comunitária. A referida instituição reforça bastante com os jovens a importância de fazerem os cursos, pois pode facilitar a inserção deles no mercado de trabalho. Tal visão é bastante presente na juventude, em geral, e nos jovens que foram entrevistados em particular. Para eles, o trabalho é uma forma de inserção e reconhecimento social. Tal perspectiva imprime à qualificação profissional um caráter que vai para além da profissionalização, traz uma perspectiva social.

O perfil dos acolhidos institucionalmente em nosso país perpassa por um recorte de gênero, classe social e etnia; e as políticas públicas para esse público alvo precisam ser debatidas e redimensionadas, visto que, não estão atingindo a eficácia necessária, pois muitos dos abrigados estão ficando mais de dois anos nos abrigos, como os jovens que participaram dessa pesquisa. 
Diante do exposto, finaliza-se afirmando que existem muitos desafios a serem enfrentados pelos jovens que estiveram em acolhimento institucional; estes desafios implicam em várias repercussões na vida desse jovem egresso, dentre elas, vale apontar a dificuldade de conseguirem se inserir na vida em comunidade e no mercado de trabalho. Os relatos obtidos no decorrer da pesquisa nos faz compreender que muitos são os desafios impostos na vida desses sujeitos, mas que com acompanhamento, orientação e efetivação de políticas públicas, eles podem ser superados.

\section{REFERENCIAS}

AZEREDO, Beatriz. Políticas públicas de emprego: tendências e possibilidades. São Paulo em Perspectiva, São Paulo, v. 11, n. 4, p. 47-59, 1997. Disponível em: 〈http://produtos.seade.gov.br/produtos/spp/v11n04/v11n04_06.pdf〉. Acesso 08 de janeiro de 2015

BRASIL. Estatuto da Criança e do Adolescente. Fortaleza: EdUECE, 2011.

. Ministério do Trabalho e Emprego. Secretaria de Políticas Públicas de Emprego. PLANFOR - Plano Nacional de Qualificação do Trabalhador. Brasília, 2001.

Ministério do Trabalho e Emprego. Secretaria de Políticas Públicas de Emprego. Plano Nacional de Qualificação - PNQ: 2003-2007. Brasília, 2003.

CARDOSO JR.; JACCOUD, Luciana. Políticas sociais no Brasil: organização, abrangência e tensões da ação estatal. In: JACCOUD, Luciana (Org.). Questão social e políticas sociais no Brasil contemporâneo. Brasília: Ipea, 2005.

CASTEL, Robert. As Metamorfoses da Questão Social. Petrópolis: Editora Vozes, 1998.

CASTRO, J. A.; AQUINO, L. M. C.; ANDRADE, C. C. (Org.). Juventude e políticas sociais no Brasil. Brasília: Ipea, 2009.

FILGUEIRAS, Cristina Almeida Cunha. Atores locais na implementação da política de qualificação profissional. Serviço Social e Sociedade, n. 107, p. 438-460, jul./set. 2011.

LIMA, A. A. A qualificação no sistema público de emprego: uma análise a partir das resoluções do CODEFAT. In: Oliveira, Roberto Véras (org.). Políticas Públicas de Qualificação: Desafios Atuais. São Paulo: A+Comunicação, 2007.

MOREIRA, Maria Idenilse. Acolhimento institucional e qualificação profissional: implicações da medida protetiva na vida do jovem egresso. 2013. 141 f. Dissertação (mestrado)- Setor de Políticas Públicas e Sociedade, Universidade $\begin{array}{lllll}\text { Estadual do Ceará, } & \text { Fortaleza, } & \text { Disponível }\end{array}$ <http://www.uece.br/politicasuece/dmdocuments/idenilse_maria_moreira.pdf>. Acesso em 28 de setembro de 2014.

MORETTO, Amilton J. O sistema público de emprego: uma construção inacabada. Tese (Doutorado) — Unicamp, Campinas, 2007.

OLIVEIRA, Régia. Jovens Trabalhadores: Representações Sobre o Trabalho na Contemporaneidade. Dissertação apresentada ao Departamento de Sociologia da Faculdade de Filosofia Letras e Ciências Humanas, Universidade de Sao Paulo, 2001.

POCHMANN, Marcio. O Trabalho Sob Fogo Cruzado: Exclusão, desemprego e precarização no final do século. São Paulo: Editora Contexto, 2002.

RAMOS, David Afonso de. Políticas Públicas Ativas de Emprego: Estudo de caso do Plano Nacional de Qualificação Profissional - PLANFOR. 2006. 136f Dissertação (Mestrado)- Programa de Pós-Graduaçao em Ciência Política. Universidade Federal de Minas Gerais, Belo Horizonte, 2006.

SANTOS, Ana. (In)sucesso escolar de crianças e jovens institucionalizadas. 2009. 165 f. Dissertação (Mestrado). Universidade Técnica de Lisboa, Lisboa, 2009.

SOARES, Mariza. Juventude e políticas de qualificação profissional ProJovem trabalhador - a experiência de Pernambuco. In. ANDRADE, Francisca Rejane Bezerra; MACAMBIRA, Júnior (Orgs). Trabalho e Formação Profissional Juventudes em Transição. Fortaleza: IDT, UECE, BNB, 2013.

SPOSITO, Marília Pontes; CARRANO, Paulo. Juventude e Políticas Públicas no Brasil. Revista Brasileira de Educação, n.24, p.1-37, set./dez. 2003. Disponível em:

<http://www.scielo.br/pdf/rbedu/n24/n24a03.pdf>. Acesso em: 09/04/2014. 